\title{
ENGINEERING JOURTIRL
}

Article

\section{Preparation of Porous Anhydrous $\mathbf{M g C l}_{2}$ Particles by Spray Drying Process}

\author{
Prachya Rojanotaikul ${ }^{1}$, Sirachaya Kunjara Na Ayudhya ${ }^{2}$, Sumet Charoenchaidet ${ }^{2}$, \\ Kajornsak Faungnawakij ${ }^{3}$ and Apinan Soottitantawat ${ }^{1, *}$ \\ 1 Center of Excellence in Particle Technology, Department of Chemical Engineering, \\ Faculty of Engineering, Chulalongkorn University, Payathai Patumwan, Bangkok 10330, Thailand \\ 2 Thai Polyethylene Co., Ltd. Map Ta Phut Industrial Estate, Muang District, Rayong 21150, Thailand \\ 3 National Nanotechnology Center, National Science and Technology Development Agency Thailand \\ Science Park, Patumtani 12120, Thailand \\ E-mail: apinan.s@chula.ac.th*
}

\begin{abstract}
Polyethylene (PE) is indispensable materials in daily lives. To produce PE, the catalyst was needed in the reaction. Ziegler-Natta catalysts were mostly used which consisted of $\mathrm{TiCl}_{4}$ on the $\mathrm{MgCl}_{2}$ supports. Polyethylene particle was reported to replicate the shape of the catalyst particles or catalyst support particles. Therefore, the $\mathrm{MgCl}_{2}$ supports need to satisfy various requirements regarding particle morphology such as shape, particle size with uniform size distribution as well as the porosity. In this research, the preparation of $\mathrm{MgCl}_{2}$ particles from irregular shape of anhydrous $\mathrm{MgCl}_{2}$ by spray drying method was studied. The moisture was reported as the poison of the catalyst, so the unusual close loop spray drying under $\mathrm{N}_{2}$ conditions was used in this study. The different types of alcohol, ethanol, $n$-propanol and $n$-butanol as solvent which was used to dissolve $\mathrm{MgCl}_{2}$ before feeding through the spray drying on the particle properties were investigated. The amount of residual alcohol (alcoholic hydroxyl group content), morphology, specific surface area, porosity and crystallinity were determined by GC method, scanning electron microscope (SEM), $\mathrm{N}_{2}$ sorption analyzer and $\mathrm{X}$-ray diffraction (XRD), respectively. The results revealed that spray drying process can produce the porous anhydrous $\mathrm{MgCl}_{2}$ particles which have rough surface, higher porosity and lower crystallinity than original anhydrous $\mathrm{MgCl}_{2}$.
\end{abstract}

Keywords: Anhydrous $\mathrm{MgCl}_{2}$, spray drying, porous $\mathrm{MgCl}_{2}$ particles.

ENGINEERING JOURNAL Volume 16 Issue 3

Received 16 November 2011

Accepted 23 February 2012

Published 1 July 2012

Online at http://www.engj.org/

DOI:10.4186/ej.2012.16.3.109

This paper is based on the oral presentation at the German-Thai Symposium on Nanoscience and Nanotechnology 2011_Green Nanotechnology of the Future, GTSNN 2011, in Nakhon Ratchasima, Thailand, 13-16 September 2011. 


\section{Introduction}

Polyolefin was well known in the name of Polyethylene (PE) or Polypropylene (PP). This polyolefin was necessary in the daily live. They were used as many materials such as packaging or containers, film, pipes, automobile parts. Catalyst was needed to produce polyolefin. The discovery of Ziegler-Natta catalysts, $\mathrm{TiCl}_{3}$ catalysts, in the 1950s led to the births of the polyolefin industry. However, the activities of the $\mathrm{TiCl}_{3}$ catalysts in first period were so low due to the step for removing catalyst residues in production process of polyolefin. In 1986, Norio Kashiwa discovered $\mathrm{MgCl}_{2}$ supported $\mathrm{TiCl}_{4}$ catalysts which have the higher activities than $\mathrm{TiCl}_{3} 100$ times with the high stereospecificity [1].

In the past 40 years, many researchers have studied the preparation method of $\mathrm{MgCl}_{2}$ for using as catalyst support in olefin polymerizations. The good supports were the good catalyst with the high activities for production of polyolefin. The preparation of $\mathrm{MgCl}_{2}$ have many methods such as ball milling [2], precipitating from dissolved $\mathrm{MgCl}_{2}$ [3-6], melt quenching or high speed mixing and quenching [7-9], seeding process [10] and spray drying [11-13].

Spray drying process can produce the porous particles from droplets by heat transfer between hot gas and droplets. Elimination of solvent in droplets was created porous structure of particles. However, it was depending on natural properties of chemical reagent. The good properties of $\mathrm{MgCl}_{2}$ support were reported as spherical shape, narrow size distribution, high porosity and low crystalline structure [7]. More porosity and lower crystal structure of $\mathrm{MgCl}_{2}$ particles was suitable for $\mathrm{Ti}$ atom to adsorb at available surface. Polymer will be growth from catalyst and $\mathrm{MgCl}_{2}$ supported catalyst. Thus, high porosity and lower crystal structure were the good properties of $\mathrm{MgCl}_{2}$ supported catalyst for highly active in polymerization of polyethylene.

In this study, the effect of the different types of alcohol; ethanol, $n$-propanol and $n$-butanol; as solvent for preparing $\mathrm{MgCl}_{2}$ particles from irregular shape of anhydrous $\mathrm{MgCl}_{2}$ by spray drying process on the porous properties of particles were investigated.

\section{Material}

Anhydrous magnesium chloride was received from Thai Polyethylene Co., Ltd (Thailand). Ethanol was purchased from Mallinckrodt, Malaysia. $N$-propanol and $n$-butanol were purchased from Quality Reagent Chemical Product (QRëc $\left.{ }^{\mathrm{TM}}\right)$, Malaysia. The chemicals used were the analytical grade to analysis. Nitrogen gas (UHP grade) was purchased from Thai Industrial Gases Public Company Limited, Thailand.

\section{Experimental}

\subsection{Preparation of Porous $\mathrm{MgCl}_{2}$ Particles}

The anhydrous $\mathrm{MgCl}_{2}$ was first mixed in the alcohols (ethanol, $n$-propanol and $n$-butanol) at $50^{\circ} \mathrm{C}$ for 1 hour until the clear solution was obtained. Then the solution was feed into spray dryer (Büchi B-290, Switzerland) to produce porous $\mathrm{MgCl}_{2}$ particle. The operating conditions of the spray drying process were as follows: gas inlet temperature: $200^{\circ} \mathrm{C}$, feed rate: $6 \mathrm{ml} / \mathrm{min}$, feed concentration $7 \mathrm{~g} \mathrm{MgCl}_{2}$ per $100 \mathrm{ml}$ of alcohol. Hot gas for drying droplets is $99.999 \%$ nitrogen gas (moisture $<5$ ppm). All step of experiment were operated under $\mathrm{N}_{2}$ atmosphere since $\mathrm{MgCl}_{2}$ was sensitive with moisture in air.

\subsection{Morphology of Spray Dried $\mathrm{MgCl}_{2}$}

The morphology of porous $\mathrm{MgCl}_{2}$ particle was investigated by scanning electron microscope (HITACHI S3400N, Japan) with the voltage of $20 \mathrm{kV}$. The $\mathrm{MgCl}_{2}$ was first spread on the stub in the glove box under $\mathrm{N}_{2}$ atmosphere. Furthermore, to move the stub to SEM chamber, the argon gas was blow to cover the sample stub to prevent moisture in the air.

\subsection{Crystallinity of Spray Dried $\mathrm{MgCl}_{2}$}

X-ray diffractometer (BRUKER D8 Advance, Germany) was analyzed crystallinity of prepared $\mathrm{MgCl}_{2}$. The angle of analysis was between $5-70^{\circ}$ with the increment at $2.4 \% \mathrm{~min}$. Mira film was used to cover the sample glass slide for preventing moisture in the air. 


\subsection{Determination of Alcohol Content}

The amount of residual alcohol was measured by GC method (SHIMADZU GC-14A, Japan) by using capillary column (DB-WAX, Agilent) and flame ionized detector (FID). Sample was prepared by dissolving $0.025 \mathrm{~g}$ of spray dried $\mathrm{MgCl}_{2}$ into the $2 \mathrm{ml}$ of water. The sample solution was injected into GC analyzer at conditions as following, column temperature at $40^{\circ} \mathrm{C}$, injection and detector temperature at $150^{\circ} \mathrm{C}$, Flow rate of nitrogen gas at $40 \mathrm{ml} / \mathrm{min}$. The external standard method was used. The amount of alcohol contents or residual alcohol was calculated.

\subsection{Porosity and Surface Area of Spray Dried $\mathrm{MgCl}_{2}$}

$\mathrm{N}_{2}$ adsorption-desorption analyzer (BELSORP-Mini-II, Japan) was used for analyzed specific surface area and porosity. The samples were pre-treated at $150^{\circ} \mathrm{C}$ for 3 hours to eliminate the residual alcohol in particles before analyzed.

\section{Results and Discussion}

\subsection{Morphology of $\mathrm{MgCl}_{2}$ Particles}

The morphology of anhydrous $\mathrm{MgCl}_{2}$ was shown in Fig. 1. The particle was irregular shape with the particle size about $500 \mu \mathrm{m}$. When the anhydrous $\mathrm{MgCl}_{2}$ was dissolved by ethanol and fed through the spray dryer, the spherical porous $\mathrm{MgCl}_{2}$ particle with rough surface was produced as shown in Fig. 2. The particle size was in the rage of $10-20 \mu \mathrm{m}$. The evaporation of alcohols in the droplet was occurred in drying step resulted in the porosity structure. Furthermore, comparing among the different types of alcohol, the spherical particles were obtained from all of the feed solvent.

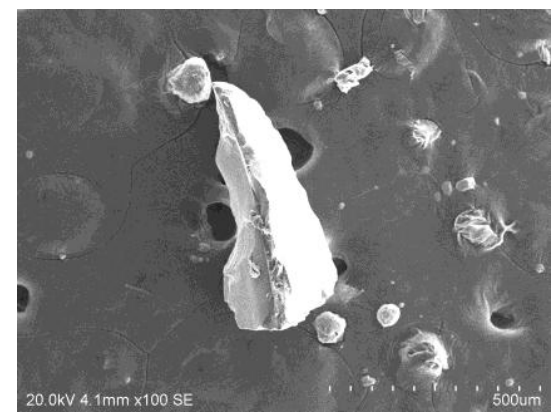

Fig. 1. Morphology of anhydrous $\mathrm{MgCl}_{2}$.

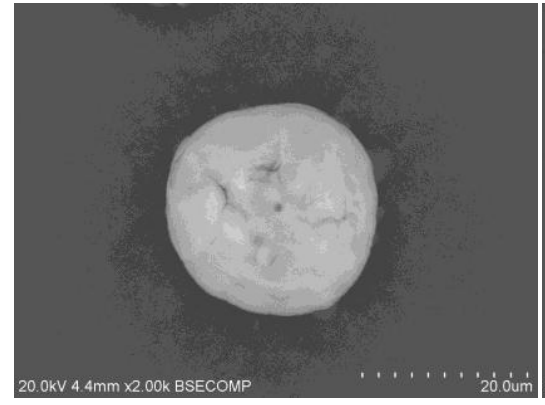

(a)

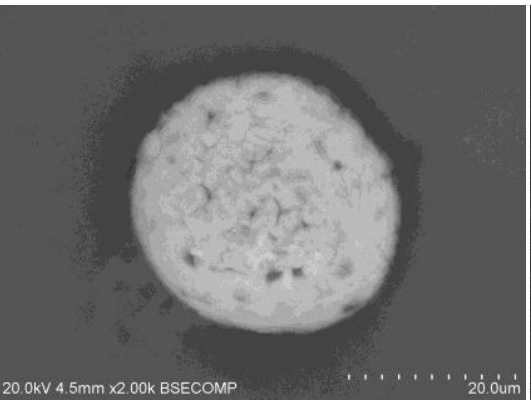

(b)

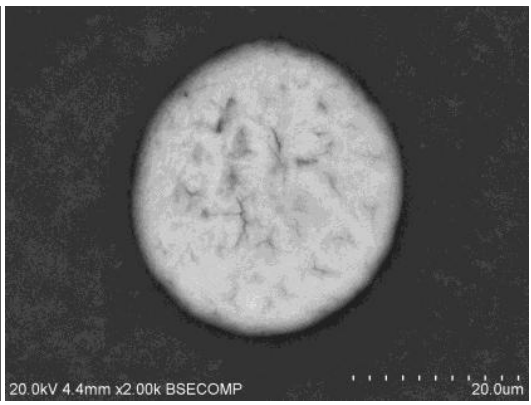

(c)

Fig. 2. Morphology of spray dried porous $\mathrm{MgCl}_{2}$ particles with (a) ethanol, (b) $n$-propanol, (c) $n$-butanol. 


\subsection{XRD Pattern of $\mathrm{MgCl}_{2}$ Particles}

XRD pattern of anhydrous $\mathrm{MgCl}_{2}$ and spray dried $\mathrm{MgCl}_{2}$ were shown in Fig. 3. Anhydrous $\mathrm{MgCl}_{2}$ was highly crystal structure. The sharp peaks were observed at $2 \theta=15^{\circ}(003), 30^{\circ}(006), 35^{\circ}$ (104). Board peak at $2 \theta=26^{\circ}$ was mira film which was used to cover the sample from the moisture in the environment. The crystalline structure of anhydrous $\mathrm{MgCl}_{2}$ was an $\alpha$-crystal type, which was generally obtained from ball milling [14]. The porous $\mathrm{MgCl}_{2}$ particles obtained from spray drying was more crystallographic disorder, evident from the absence of the sharp peak at 003 planes especially in the case of $n$-propanol and $n$-butanol solvent.

The performance of support to activate a particular catalyst depends on degree of crystallographic disorder. The higher crystallographic disorder was reported to be suitable for transition metal catalysts [15]. The results indicate that all alcohols using in this research can decrease the crystal structure of $\alpha-\mathrm{MgCl}_{2} \cdot n-$ Propanol can destroy the crystal structure which was higher than $n$-butanol and ethanol respectively.

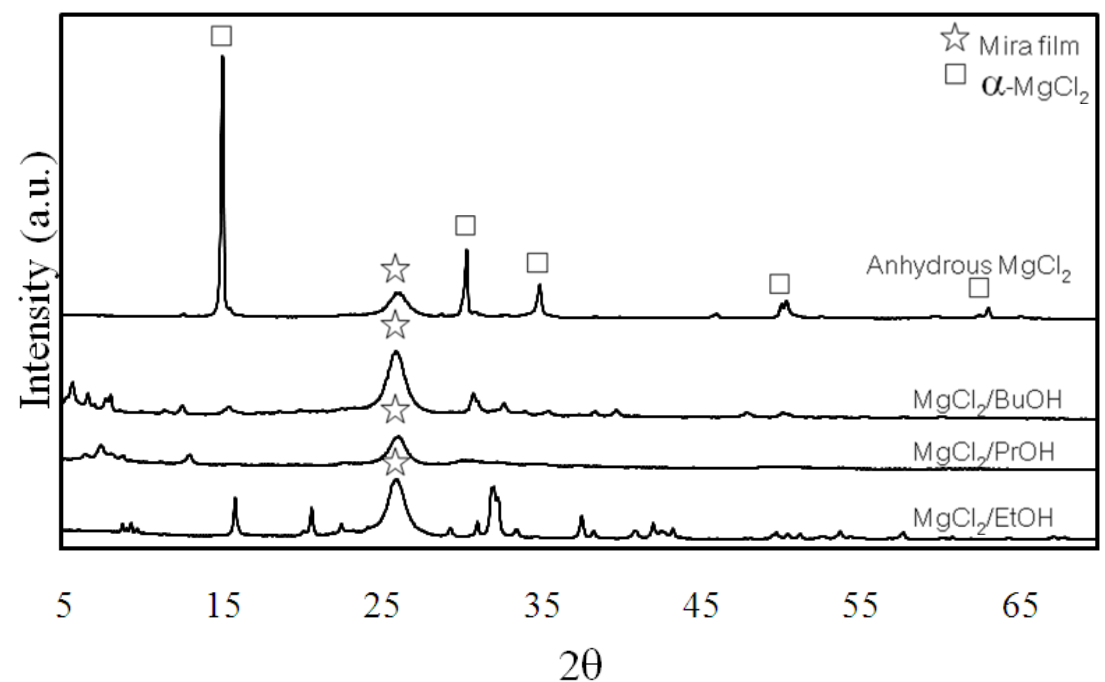

Fig. 3. XRD pattern of anhydrous $\mathrm{MgCl}_{2}$ and porous $\mathrm{MgCl}_{2}$ particles.

\subsection{Residual Alcohol in $\mathrm{MgCl}_{2}$ Particles}

Residual alcohols ( $\mathrm{ROH} / \mathrm{MgCl}_{2}$ molar ratio) in $\mathrm{MgCl}_{2}$ particles were shown in Table 1. The results reveal that ethanol was least remained in the particles due to lowest boiling point. However, $n$-propanol was remained more than $n$-butanol despite of $n$-butanol have higher boiling point. Because of the crystal structure, $\mathrm{MgCl}_{2} / \mathrm{PrOH}$ gave the higher disorder than $\mathrm{MgCl}_{2} / \mathrm{BuOH}$. These indicate that $n$-propanol can attach in the structure of $\mathrm{MgCl}_{2}$ very well. Consequently, residual alcohol of $\mathrm{MgCl}_{2} / \mathrm{PrOH}$ was higher than $\mathrm{MgCl}_{2} / \mathrm{BuOH}$ and $\mathrm{MgCl}_{2} / \mathrm{EtOH}$, respectively. It was consistency with the XRD results. In 2008, Robin Huang et al studied the different of ethanol remained in the $\mathrm{MgCl}_{2}$ supported. The results shown that higher residual ethanol in particles gave lower crystallographic disorder. In the other hand, lower residual ethanol gave higher crystallographic disorder which consistent with this research [16].

Table 1. Residual alcohol in $\mathrm{MgCl}_{2}$ particles.

\begin{tabular}{lcr}
\hline Sample & Initial Molar Ratio & Final Molar Ratio \\
\hline $\mathrm{MgCl}_{2} / \mathrm{EtOH}$ & 23.28 & $0.04 \pm 0.03$ \\
$\mathrm{MgCl}_{2} / \mathrm{PrOH}$ & 18.17 & $0.97 \pm 0.02$ \\
$\mathrm{MgCl}_{2} / \mathrm{BuOH}$ & 14.86 & $0.85 \pm 0.08$ \\
\hline
\end{tabular}




\subsection{Surface Area and Porosity of $\mathrm{MgCl}_{2}$ Particles}

Surface area and porosity is the one important factor for good supported catalyst. The results of surface area and pore volume were shown in Table 2. The anhydrous $\mathrm{MgCl}_{2}$ was non porous particles with low surface area. However, the spray dried $\mathrm{MgCl}_{2}$ particles has a surface area higher than anhydrous $\mathrm{MgCl}_{2}$ $\mathrm{MgCl}_{2} / \mathrm{EtOH}$ has highest surface area and pore volume, next is $\mathrm{MgCl}_{2} / \mathrm{BuOH}$ and $\mathrm{MgCl}_{2} / \mathrm{PrOH}$ respectively. These results were consistent with the residual alcohol as in previous section. When residual alcohol decreased, surface area and pore volume of particles was increased since the elimination of alcohol will create the new available surface.

Table 2. Surface area and pore volume of $\mathrm{MgCl}_{2}$ particles.

\begin{tabular}{lcr}
\hline Sample & $\begin{array}{r}\text { Specific surface area } \\
\left(\mathbf{m}^{2} / \mathbf{g}\right)\end{array}$ & $\begin{array}{r}\text { Pore volume } \\
\left(\mathbf{c m}^{\mathbf{3}} \mathbf{g}\right)\end{array}$ \\
\hline Anhydrous $\mathrm{MgCl}_{2}$ & 2.77 & 0.0024 \\
$\mathrm{MgCl}_{2} / \mathrm{EtOH}$ & 29.91 & 0.0438 \\
$\mathrm{MgCl}_{2} / \mathrm{PrOH}$ & 12.88 & 0.0371 \\
$\mathrm{MgCl}_{2} / \mathrm{BuOH}$ & 14.57 & 0.0411 \\
\hline
\end{tabular}

$\mathrm{MgCl}_{2} / \mathrm{EtOH}$ has the highest surface area because of lower boiling point of ethanol than $n$-propanol and $n$-butanol as Fig. 4. The $\mathrm{MgCl}_{2} / \mathrm{PrOH}$ showed the lowest surface area. When consider XRD pattern of $\mathrm{MgCl}_{2} / \mathrm{PrOH}$ in Fig. 3, the results show that PrOH can destroy crystal structure very well. It was probably that $\mathrm{PrOH}$ can attach with $\mathrm{MgCl}_{2}$ within particle.

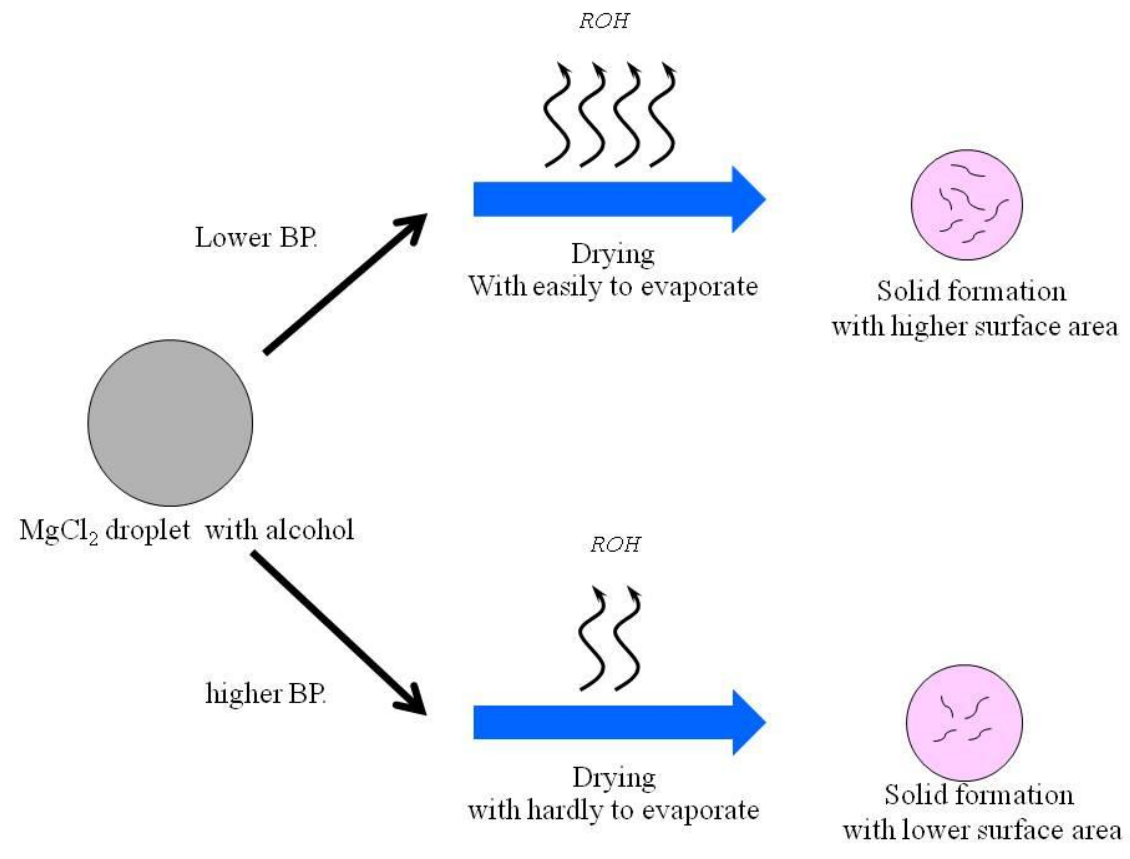

Fig. 4. Model for explanation of porosity generation in particles.

\section{Conclusion}

The spray drying process can be used to produce porous $\mathrm{MgCl}_{2}$ particles for supported catalyst in ethylene polymerization. During the spray drying process, the alcohol was eliminated from droplet to produce porous particles. In the dissolving step, three types of alcohol can destroy crystal structure of anhydrous $\mathrm{MgCl}_{2}$ as a result of crystallographic disorder or amorphous structure. Ethanol gave the highest surface area and pore volume. $N$-propanol gave the highest crystallographic disorder. 


\section{Acknowledgement}

The authors gratefully acknowledge Chulalongkorn University Graduate Scholarship to Commemorate the $72^{\text {nd }}$ Anniversary of His Majesty King Bhumibol Adulyadej. Thai Polyethylene Co., Ltd. National Nanotechnology Center (NANOTEC, Thailand) and the Centennial Fund of Chulalongkorn University to the Center of Excellence in Particle Technology.

\section{References}

[1] K. Norio, "The discovery and progress of $\mathrm{MgCl}_{2}$ supported $\mathrm{TiCl}_{4}$ catalysts," Journal of Polymer Science Part A: Polymer Chemistry, vol. 42, no. 1, pp. 1-8, 2004.

[2] G. D. Bukatov, S. A. Sergeev, V. A. Zakharov, and A. G. Potapov, "Supported titanium-magnesium catalysts for propylene polymerization," Kinetics and Catalysis, vol. 49, no. 6, pp. 782-790, 2008.

[3] J. H. Choi, J. S. Chung, H. W. Shin, I. K. Song, and W. Y. Lee, "The effect of alcohol treatment in the preparation of $\mathrm{MgCl}_{2}$ support by a recrystallization method on the catalytic activity and isotactic index for propylene polymerization," European Polymer Journal, vol. 32, no. 4, pp. 405-410, 1996.

[4] J. S. Chung, J. H. Choi, I. K. Song, W. Y. Lee, "Effect of ethanol treatment in the preparation of $\mathrm{MgCl}_{2}$ support for the propylene polymerization catalyst," Macromolecules, vol. 28, no. 5, pp. 1717-1718, 1995.

[5] P. Brems and G. L. G. Debras, "Olefin polymerization catalyst based on magnesium chloride complexes," U.S. Patent 5492 984, Feb 20, 1996.

[6] L. Luciani, M. Pondrelli, and R. Invernizzi, "Method for preparing a solid catalyst component for ethylene (co)polymerization," U.S. Patent 5173 465, Dec 22, 1992.

[7] E. JalaliDil, S. Pourmahdian, M. Vatankhah, and F. A. Taromi, "Effect of dealcoholation of support in $\mathrm{MgCl}_{2}$-supported Ziegler-Natta catalysts on catalyst activity and polypropylene powder morphology," Polymer Bulletin, vol. 64, no. 5, pp. 445-457, 2009.

[8] M. C. Forte and F. M. B. Coutinho, "Highly active magnesium chloride supported ziegler-natta catalysts with controlled morphology," European Polymer Journal, vol. 32, no. 2, pp. 223-231, 1996.

[9] Z. Ma, L. Wang, W. Wang, J. Wang, and H. Yu, "Study of propylene polymerization catalyzed by spherical $\mathrm{MgCl}_{2}$-supported ziegler-natta catalyst system: Preparation of spherical support," Polymer Plastics Technology and Engineering, vol. 44, no. 8-9, pp. 1475-1483, 2005.

[10] D. D. Klendworth, M. K. Reinking, and E. D. Kist, "Magnesium chloride support," U.S. Patent 7402 546, July 222008.

[11] R. Invernizzi, F. Ligorati, M. Fontanesi, and R. Catenacci, "Supported catalysts for the polymerization of ethylene," U.S. Patent 4421 674, Dec. 20, 1983.

[12] J. C. Chadwick and J. C. van der Sar, "Preparation of spherical magnesium alkoxide particles," U.S. Patent 4728 704, 1988.

[13] T. Jiang, W. Chen, F. Zhao, Y. Liu, R. Wang, H. Du, and T. Zhang, "Preparation of porous spherical $\mathrm{MgCl}_{2} / \mathrm{SiO}_{2}$ complex support as precursor for catalytic propylene polymerization," Journal of Applied Polymer Science, vol. 98, no. 3, pp. 1296-1299, 2005.

[14] Z.-Y. Ye, L. Wang, L.-F. Feng, X.-P. Gu, H.-H. Chen, P.-Y. Zhang, J. Pan, S. Jiang, and L.-X. Feng, "Novel spherical Ziegler-Natta catalyst for polymerization and copolymerization. I. Spherical $\mathrm{MgCl}_{2}$ support," Journal of Polymer Science, Part A: Polymer Chemistry, vol. 40, no. 18, pp. 3112-3119, 2002.

[15] R. Xu, D. Liu, S. Wang, and B. Mao, "Preparation of spherical $\mathrm{MgCl}_{2}$-supported late-transition metal catalysts for ethylene polymerization," Macromolecular Chemistry and Physics, vol. 207, no. 8, pp. 779-786, 2006.

[16] R. Huang, F. Malizia, G. Pennini, C. E. Koning, J. C. Chadwick, "Effects of $\mathrm{MgCl}_{2}$ crystallographic structure on active centre formation in immobilized single-centre and Ziegler-Natta catalysts for ethylene polymerization," Macromolecular Rapid Communications, vol. 29, no. 21, pp. 1732-1738, 2008. 